\title{
A Simple Method for Quantifying Light Transmission through Fish-eye Photographs of Plant Canopies
}

\author{
B. Schaffer, R.C. Ploetz, and L.J. Mason \\ Tropical Research and Education Center, Institute of Food and \\ Agricultural Sciences, University of Florida, 18905 S. W. 280th Street, \\ Homestead,. FL 33031
}

Additional index words. hemispherical photography, light transmission

Fish-eye (hemispherical) photography can be used to provide useful information to estimate plant canopy densities (Anderson, 1974). The techniques used to quantify light transmission through photographic negatives of such canopies, however, are often timeconsuming (Anderson, 1964) or require expensive equipment (Lakso, 1976, 1980; Smart, 1975). Therefore, we devised a simple technique for quantifying the percentage of sky in fish-eye photographs of plant canopies using less expensive and more readily available equipment.

The apparatus consisted of a line-quantum sensor (LI-COR model 190SA, LI-COR, Lincoln, Neb.) attached horizontally to the bottom of a motorized projector screen. The screen moved up or down at a rate of 0.16 $\mathrm{m} \cdot \mathrm{s}^{-1}$. Any motorized system for moving the sensor at a constant rate can be substituted for the screen as long as the sensor remains horizontal. The quantum sensor was connected to a millivolt adapter (LI-COR) that was connected to a strip-chart recorder. Photographic negatives were mounted in standard plastic slide-mounts and projected onto the screen from a slide projector. The size of the focused image was adjusted to the width of the quantum sensor, and the entire height of the image was then scanned from top to bottom in a dark room by automatically lowering the projector screen. The percentage of radiation $(400-700 \mathrm{~nm}$ wavelength) transmitted through the image was represented as a profile on the recorder. The chart speed on the recorder was adjusted to broaden the profile so that the area beneath the curve could be measured accurately with an electronic digitizer (Jandel Scientific, Sausalito, Calif.) connected to an IBM personal computer. A simple planimeter could also be used. A simpler and more accurate technique for estimating profile area could be obtained by using an electronic integrator

\footnotetext{
Received for publication 7 May 1990. Florida Agricultural Experiment Station Journal Series no. R00243. We thank A.N. Lakso and T.L. Robinson for providing fish-eye photographs and corresponding data. The cost of publishing this paper was defrayed in part by the payment of page charges. Under postal regulations, this paper therefore must be hereby marked advertisement solely to indicate this fact.
}

instead of a strip-chart recorder.

The system was calibrated by placing a series of nonexposed (opaque) negatives in slide mounts. Holes were punched in the opaque slides to create a range of standards with $0 \%$ (no holes) to $100 \%$ (slide mount only) of the slide area removed. After projecting, scanning, recording, and digitizing light transmission through the standardized set of negatives, linear regression was used to compare the percentage of area removed from the slides with light transmission determined with the digitized profile (Fig. 1); the data were highly correlated.

The system was tested with negative photographs of apple tree canopies taken with a fish-eye lens. These negatives had previously been quantitated by false-color densitometry (A.N. Lakso and T.L. Robinson, personal- communication). The camera and lens used to take these photographs has been described by Lakso (1976). The percentage of light transmission determined by our method was linearly correlated $\left(r^{2}=0.86\right)$ with the percentage of sky determined by false-color densitometry (Fig. 2).

Although the simple method we describe is useful for determining relative differences in canopy densities from fish-eye photographs, there are two potential disadvantages. First, fish-eye lenses are not equalarea projection lenses; from the zenith to the edge of the photographic image, the area within the photographic image becomes proportionately larger than the area within the actual plant canopy. Thus, canopy gaps near the horizon will give a disproportionately high percentage of sky compared to gaps at the zenith. When using false-color densitometry, correction factors for the distortion can be programmed into the operations software (A.N. Lakso, personal communication). The ability to eliminate this distortion is not available with the system we describe here. However, Lakso (1976) noted that distortion in these photographs can be reduced by masking the outer $40 \%$ of the image, where most of the distortion occurs. Possible distortion can also be minimized by placing a series of opaque concentric rings over the negative and scanning the negative once for each ring. This would provide a series of light measurements, each for a different angle from the zenith. Each scan could then be

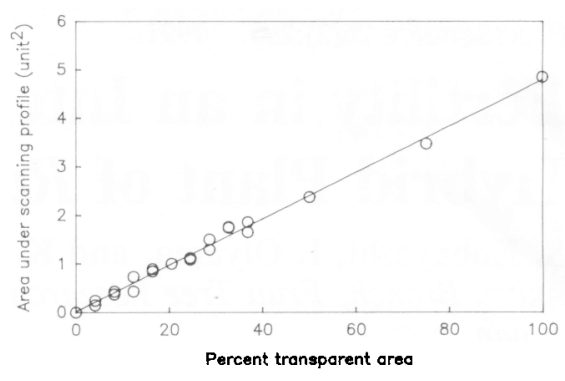

Fig. 1. Percent transparent area and quantum sensor scans of projected image through opaque film; units are on an arbitrary scale used on the plotter. The regression line is defined by the equation: $\mathrm{y}=0.02+0.048 \mathrm{x}, r^{2}=0.98$.

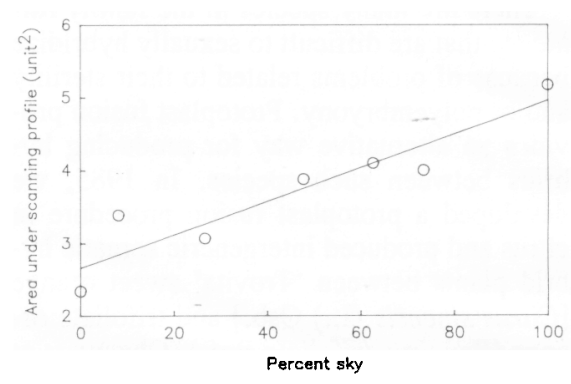

Fig. 2. Percent sky determined with false-color densitometry and quantum sensor scans of projected image of negatives of fish-eye photographs of apple canopies; units are on an arbitrary scale used on the plotter. The regression line is represented by the equation: $\mathrm{y}=2.66+0.023 \mathrm{x}$, $r^{2}=0.86$

multiplied by a factor to account for the zenith angle. Another disadvantage with the system we describe is the solar angle position, which can affect light penetration within plant canopies. This aspect can be accounted for with densitometry software, but cannot be accounted for by our method, Therefore, all canopy photographs must be taken within a fairly short time span or on uniformly overcast days to avoid influence by solar angle. Despite these drawbacks, the system we describe is simple to construct and useful for quantitating light transmission through fisheye photographs of plant canopies.

\section{Literature Cited}

Anderson, M.C. 1964. Studies of the woodland light climate. I. The photographic computations of light conditions. J. Ecol. 52:27-41.

Anderson, M.C. 1974. Radiation and crop structure, p. 412-466. In: Z. Sestak, J. Catsky, and P.G. Jarvis (eds.). Plant photosynthetic production, manual of methods. W. Junk, The Hague, Netherlands.

Lakso, A.N. 1976. Characterizing apple tree canopies by fisheye photography. HortScience 11:404-405.

Lakso, A.N. 1980. Correlation of fisheye photography to canopy structure, light climate, and biological responses to light in apple trees. J. Amer. Soc. Hort. Sci. 105:43-46.

Smart, R.E. 1975. Implications of the radiation microclimate for productivity of vineyards. $\mathrm{PhD}$ Diss., Cornell Univ., Ithaca, N.Y. 